\title{
Electrospun Sodium Alginate/Polyethylene Oxide Fibers and Nanocoated Yarns
}

\author{
C. Hu, R. H. Gong, and F. L. Zhou \\ Textiles, School of Materials, The University of Manchester, Manchester M13 9PL, UK \\ Correspondence should be addressed to R. H. Gong; hugh.gong@manchester.ac.uk
}

Received 22 February 2015; Accepted 17 May 2015

Academic Editor: Jan-Chan Huang

Copyright (C) 2015 C. Hu et al. This is an open access article distributed under the Creative Commons Attribution License, which permits unrestricted use, distribution, and reproduction in any medium, provided the original work is properly cited.

Sodium alginate (NaAlg), as a natural biopolymer, was electrospun from aqueous solution via blending with a biofriendly synthetic polymer polyethylene oxide. The morphology and chemical properties of resultant alginate-based nanofibers were characterized by using scanning electron microscopy (SEM), Fourier transform infrared spectroscopy (FTIR), powder X-ray diffractometer (PXRD), and differential scanning calorimetry (DSC). At a wide voltage window (i.e., $12-24 \mathrm{kV}$ ), smooth and uniform nanofibers were obtained from the $5.0 \%$ concentration with the NaAlg/PEO ratio ranging from 1:1 to $1: 3$. The results from FTIR, PXRD, and DSC demonstrate that molecular interaction exists between these two polymers and, therefore, contributes to the alteration of crystallinity of electrospun fibers. In addition, $\mathrm{NaAlg} / \mathrm{PEO}$ nanofiber-coated polylactic acid (PLA) yarns with different twist levels were also fabricated in this work. The results show that the tensile strength of the nanocoated hybrid yarn and the tensile strength of uncoated yarn increase with the twist per centimeter (TPC) up to 0.5 but decrease when TPC is further increased. The tensile properties of hybrid yarn are superior to those of the uncoated yarn.

\section{Introduction}

Alginate is a generic name for the salts of alginic acid that can be extracted from the cell wall of brown seaweeds or synthesized via the metabolism of some bacteria $[1,2]$. As a group of linear copolymer polysaccharide molecule, alginates are composed of uronic acid residues with a carboxyl group linked with the carbon outside the ring structure [3]. The synthesis of alginates involves the combination of two main monomers: mannuronic acid (M-unit) and guluronic acid (G-unit). Through the random assembly of these two acidic monomers, three types of sequences including polymannuronic acid (M-blocks), polyglucuronic acid (G-blocks), and MG-blocks can be formed with their unique spatial configurations [4]. Due to the $\beta-1-4$ linkage existing in $\mathrm{M}$ block, it shows a linear and flexible structural conformation that can be swelled enormously and is mainly in the leaves of alginate. However, the G-block presents a folded and rigid configuration that is only swelled slightly because of its internal $\alpha-1-4$ linkage. Thus, it is mainly in the stem of alginate so as to provide stiffness for the molecular chains $[5,6]$. Generally, alginates are insoluble in organic solvents but can be dissolved in water. When it is put in aqueous solution, the special conformation of G-block exhibits a strong tendency in binding bivalent metal cations with guluronic acids [7]. This binding behavior with cations also facilitates the collaborative combining with different molecules of the polymer, which leads to the emergence of ionotropic gel [4]. Therefore, the extent of gelation for alginic acids largely relies on the percentage of G-blocks inside the entire molecular structure. By virtue of its unique advantages, including biodegradability, biocompatibility, affinity with cell seeding and growth, nontoxicity, hydrophilicity, and relatively low cost, alginate has been widely used in biomedical industry (e.g., tissue scaffolding, wound dressing, skin healing, and drug delivery carrier) $[8,9]$. With respect to conventionally manufactured alginate fiber with a diameter of tens or hundreds microns, nanoscale electrospun fibers can enhance the efficiency for some specific end-uses [10].

Normally, owing to the limited solubility and high viscosity of this natural polyelectrolytic polymer, electrostatic spinning of pure alginate is a big challenge [11]. In order to solve this issue, flexible and uncharged synthetic polymers (e.g., PEO and PVA) can be added to improve its spinnability 
$[12,13]$. Via the hydrogen bonds formed between alginate and these polymers, the repulsive force among polyanionic molecules is to a large extent decreased to facilitate the chain entanglement, which eventually allows the production of nanofibers [14]. $\mathrm{Lu}$ and his group investigated the electrospinnability of sodium alginate/PEO with a concentration ranging from $1 \%$ to $4 \%$ [15]. Only $3 \%$ solution can be employed to make smooth and even nanofibers with their average diameters around $250 \mathrm{~nm}$. Bhattarai and Zhang found that the viscosity of the solution was an important element in regulating the spinnability [16]. By the extra addition of some surfactants (e.g., Triton X-100 and DMSO), the solution viscosity can be changed so as to improve the spinning capacity [17]. The structural integrity of resultant nanofiber mats can be strengthened via cross-linking with metal ion (e.g., $\mathrm{Ca}^{2+}$ and $\mathrm{Mg}^{2+}$ ) to fabricate a more durable tissue scaffolding material [18]. Likewise, the morphology of nanofiber mats was maintained by using a glutaraldehyde double cross-linking and the addition of polylysine in the study of Leung and his coworkers [19]. In 2011, Fang et al. produced a relatively pure alginate fiber by only introducing $\mathrm{Ca}^{2+}$ into the sodium alginate solution. This success of this process was ascribed to the increase of intermolecular interactions and the decrease of surface tension [20].

Coating on textile materials is usually employed to endow them with particular properties such as stability, tensile strength, abrasion or chemical resistance, and appearance effects [21]. Apart from the traditional techniques including dip coating, spray coating, drop coating, physical vapor deposition coating, and melt coating, electrospinning coating (ESC) provides a new alternative due to its capacity to produce and apply micro- or nanoscale fibers with higher specific surface area, leading to smaller pores and higher porosity on the substrate [22-24]. For instance, by coating electrospun polyamide-66 nanofibers on four different fibrous substrates, Heikkla et al. found that the filtration efficiency of submicron aerosol particles was enhanced by up to $90 \%$ compared to the uncoated samples [25]. Lee and Obendorf fabricated a protective clothing material with higher air permeability and water vapor transmission by laminating the polypropylene web from melt electrospinning onto nonwoven fabric substrates [26]. Recently, polymer nanofiber coating on the surface of a variety of substrates has also been studied for specific applications, including flame retardancy, battery separator, corrosion inhibitor, cartilage regeneration, and spray impact cooling [27-31]. However, owing to the relatively low mechanical strength and strain capacity, nanofiber layers are susceptible to rupture and delamination from the surface of textile substrates, reducing their durability $[25,32]$. In order to avoid this drawback, some attempts have been made to enhance the adhesion of electrospun fiber mats on substrate surface, such as lowtemperature oxygen plasma treatment and nanocoating on yarns or filaments $[23,33]$.

In this paper, the electrospinning of alginate-based nanofibers from aqueous solution is reported. By blending sodium alginate with PEO, the morphology and chemistry of resultant electrospun nanofibers were systematically

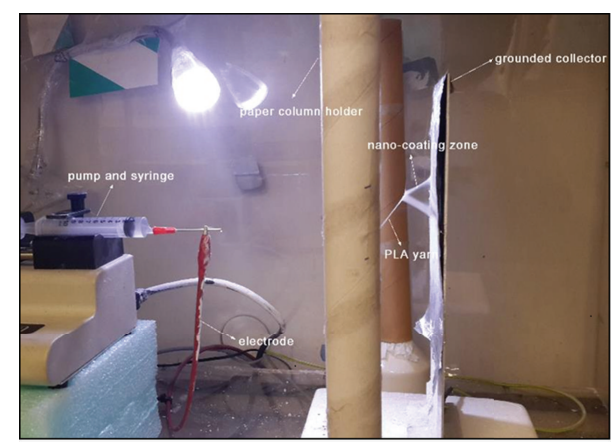

FIGURE 1: Nanocoating on the PLA yarn by electrospinning.

investigated with a combination of a series of parameters, including solution concentration, electric voltage, and $\mathrm{NaAlg} / \mathrm{PEO}$ ratio. Moreover, alginate-based nanofiber-coated PLA yarns with different twist levels were fabricated with the aim of integrating the mechanical strength of PLA yarn with the greater biocompatibility of alginate-based nanofibers. Based on our previous research on nanocoated yarns by ESC, the tensile strength of this hybrid yarn was further compared with the uncoated counterpart $[23,32]$. This provides a new understanding of the tensile strength of $\mathrm{NaAlg} / \mathrm{PEO}$ nanofiber-coated yarns, which is valuable in using nanocoated yarns to fabricate fabric structures for biological and medical applications such as wound dressing and sutures.

\section{Experimental}

2.1. Materials. PLA yarn composed of 216 multifilaments was provided by China Haining Xin Gao Fibers Co. Ltd. Polyethylene oxide (PEO) powder with average molecular weight (Mv) of 900,000 was purchased from Sigma-Aldrich Co. Ltd. Sodium alginate derived from brown algae was kindly provided by Convatec Inc. Deionized water as the solvent was obtained via the treatment of PURELAB 3000 (ELGA LabWater Co.). All the chemicals were used without any further purification.

2.2. Solution Preparation. PEO and sodium alginate were dissolved into deionized water at room temperature. In order to gain homogeneous solution, the mixture was stirred gently by a rotating magnetic mixer (Kika Labortechnik RCT Basic Heater/Stirrer) for $24 \mathrm{~h}$ prior to electrospinning. Different concentrations (1-5\%) and ratios (1:0-0:1) of NaAlg/PEO blended solutions were prepared for the following study.

2.3. Electrospinning and ESC Process. During electrospinning, each solution was loaded into a $10 \mathrm{~mL}$ plastic syringe capped with a blunt needle. The syringe infusion pump was employed to control the feed rate of solution at $0.4 \mathrm{~mL} / \mathrm{h}$. An electrode connected with the high-voltage power supply was clamped onto the needle via its alligator clip to provide the positive voltage ranging from 0 to $30 \mathrm{kV}$. The aluminum collecting plate covered with foil was placed at a fixed distance 

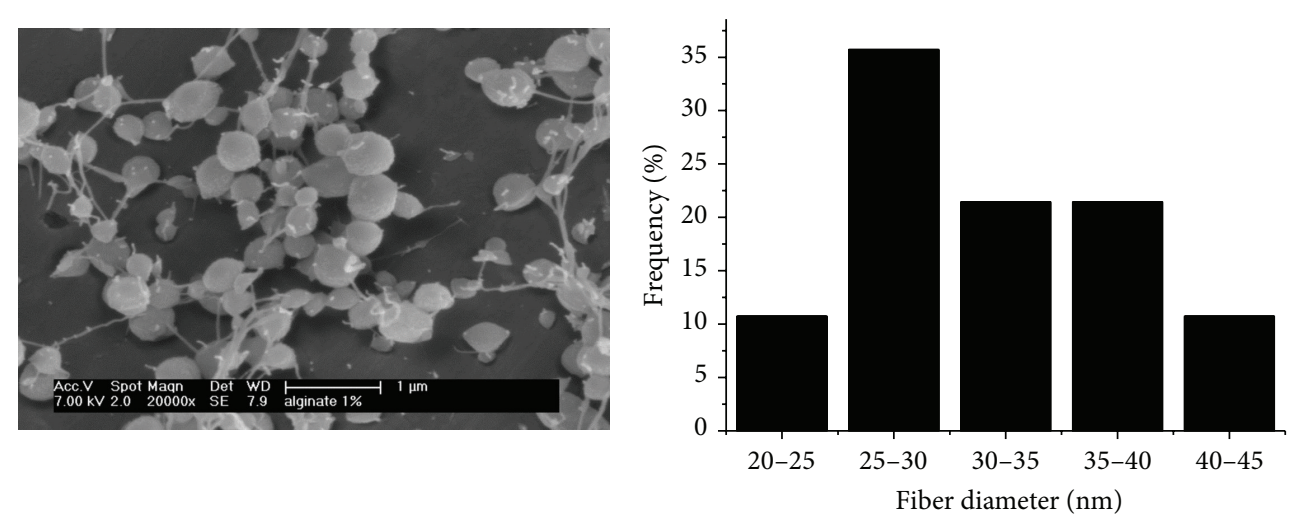

(a)
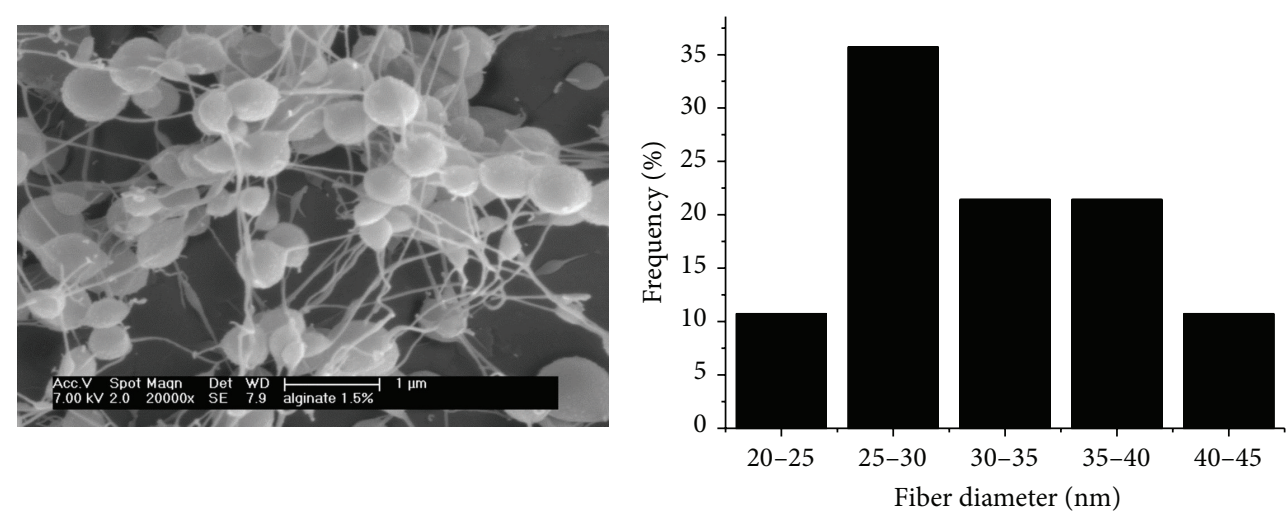

(b)
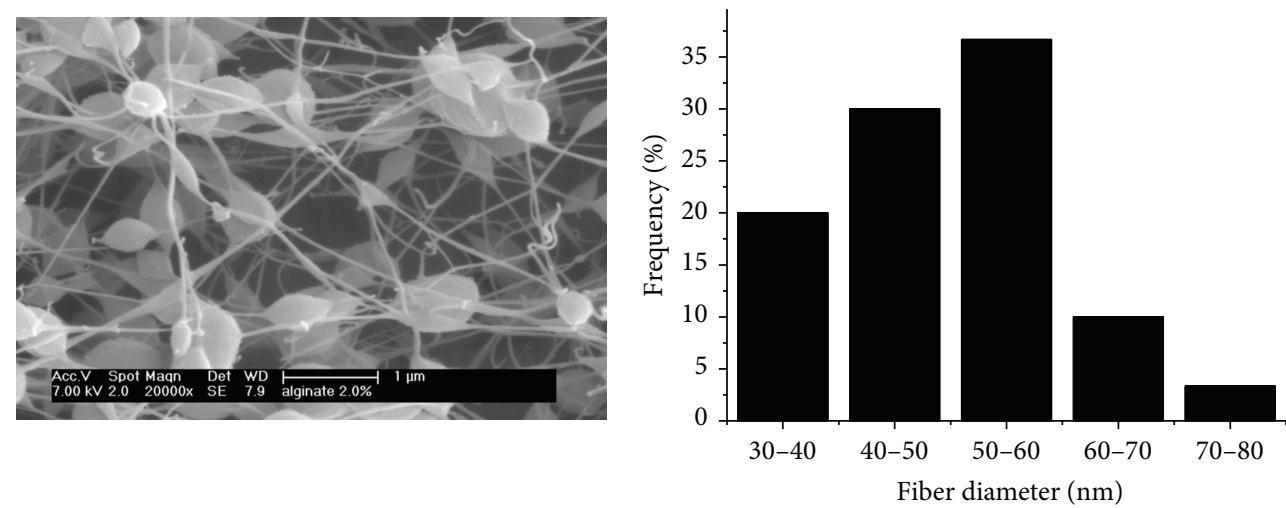

(c)
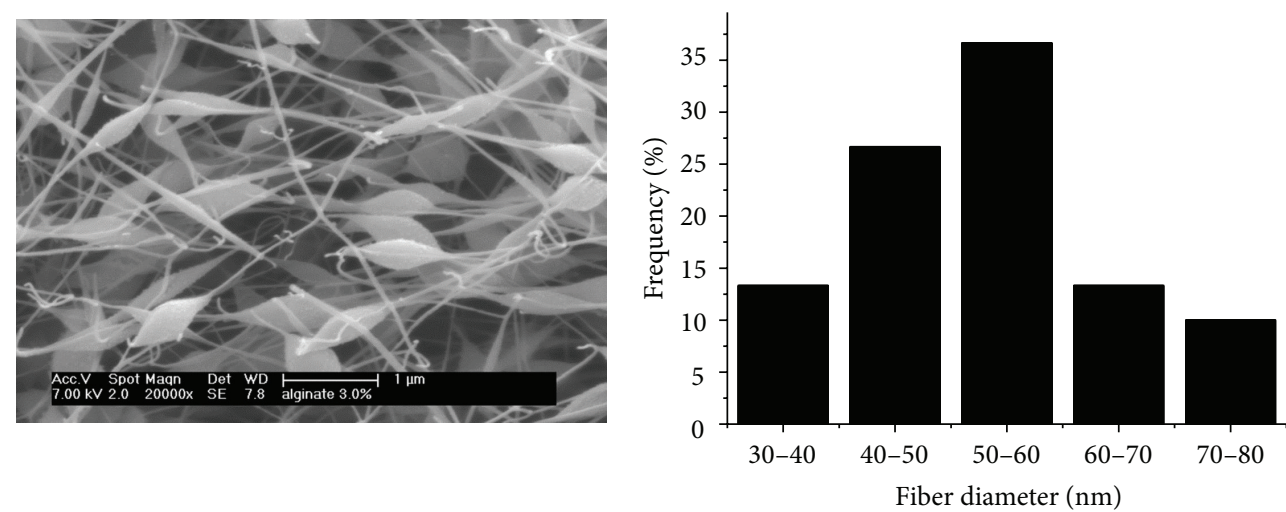

(d)

FIGURE 2: Continued. 

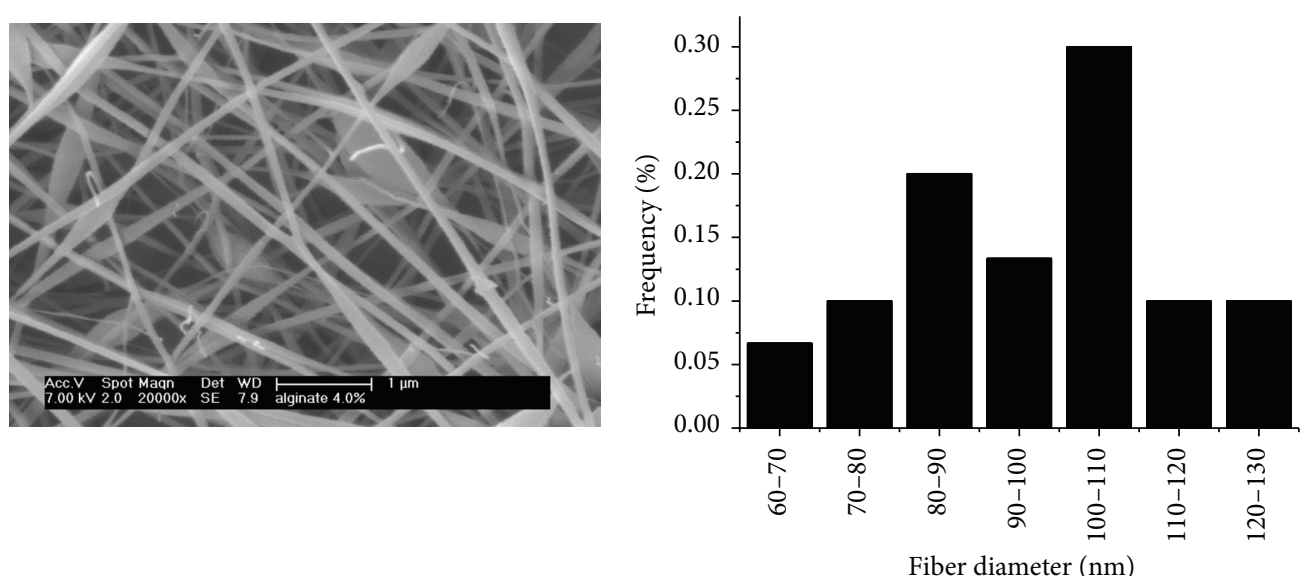

(e)
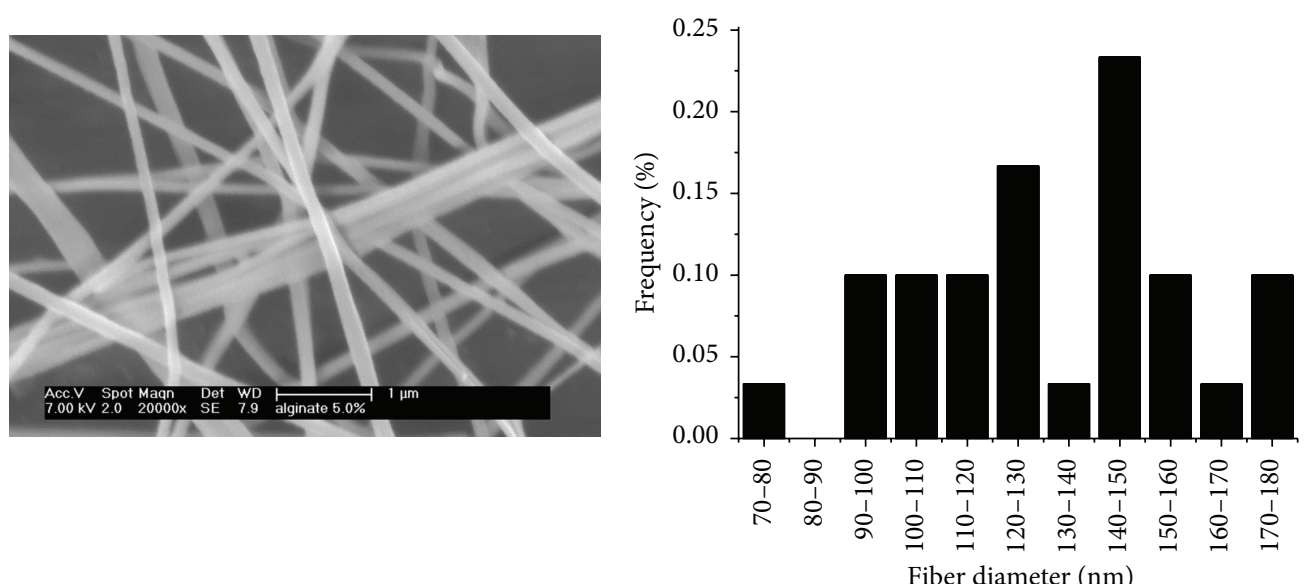

(f)

Figure 2: Effect of solution concentration on fiber morphology and diameter distribution with $1: 1 \mathrm{NaAlg} / \mathrm{PEO}$ ratio (magnification $=$ 20,000x). Solution concentration: (a) $1 \%$; (b) $1.5 \%$; (c) $2 \%$; (d) $3 \%$; (e) $4 \%$; (f) $5 \%$.

of $16 \mathrm{~cm}$ from the needle tip. All the spinning operations and drying of as-spun nanofibers were conducted at ambient conditions. For the ESC process, the only difference of the electrospinning setup was the utilization of two paper columns as the support of PLA yarn for nanocoating. The original PLA yarn with a constant length of $25 \mathrm{~cm}$ was stuck to these two columns at a fixed height to ensure that the central part of deposited nanofibers could be collected by the yarns. The coating distance between the needle tip and the nanocoated yarn was fixed at $13 \mathrm{~cm}$. Figure 1 illustrates the $\mathrm{NaAlg} / \mathrm{PEO}$ nanofiber coating by electrospinning with the formation of a triangular coating mat on the PLA yarn.

2.4. Twisting of Yarns. Both NaAlg/PEO nanofiber-coated and uncoated PLA yarns with the length of $25 \mathrm{~cm}$ were twisted by using a twist counter (James H. Heal Co. Ltd.). Each single yarn from these two groups was twisted into five different levels: 0 TPC, 0.5 TPC, 1.0 TPC, 3.0 TPC, and 5.0 TPC.
2.5. Characterization. A small piece of sample was prepared via cutting from the electrospun nanofiber mat deposited on the aluminum foil and then adhered to a specimen stub with carbon tape. With the view of minimizing charging effect, the nanofiber sample was sputtered a thin layer of gold or carbon by Edwards S150B Sputter Coater or precision etching coating system (Model 682, Gatan Inc.). After that, the stub with alginate nanofiber was placed into a Philip XL-30 SEM (SEMTech Solutions Inc.) and imaged with magnification of 20,000x for morphological and dimensional characterization. For each image, at least 30 different points were randomly chosen to measure their average diameter. With the application of NIH ImageJ software, fiber diameters were calculated from the image through converting pixels to corresponding standard unit of length. Infrared spectra were obtained by employing the Nicolet 5700 FTIR (Thermo Scientific Inc.) with the scanning scope ranging from 600 to $4000 \mathrm{~cm}^{-1}$ at a resolution of $4 \mathrm{~cm}^{-1}$ to explore the change in molecular structure of alginate nanofibers electrospun from different ratios of alginate to PEO. Powder X-ray 

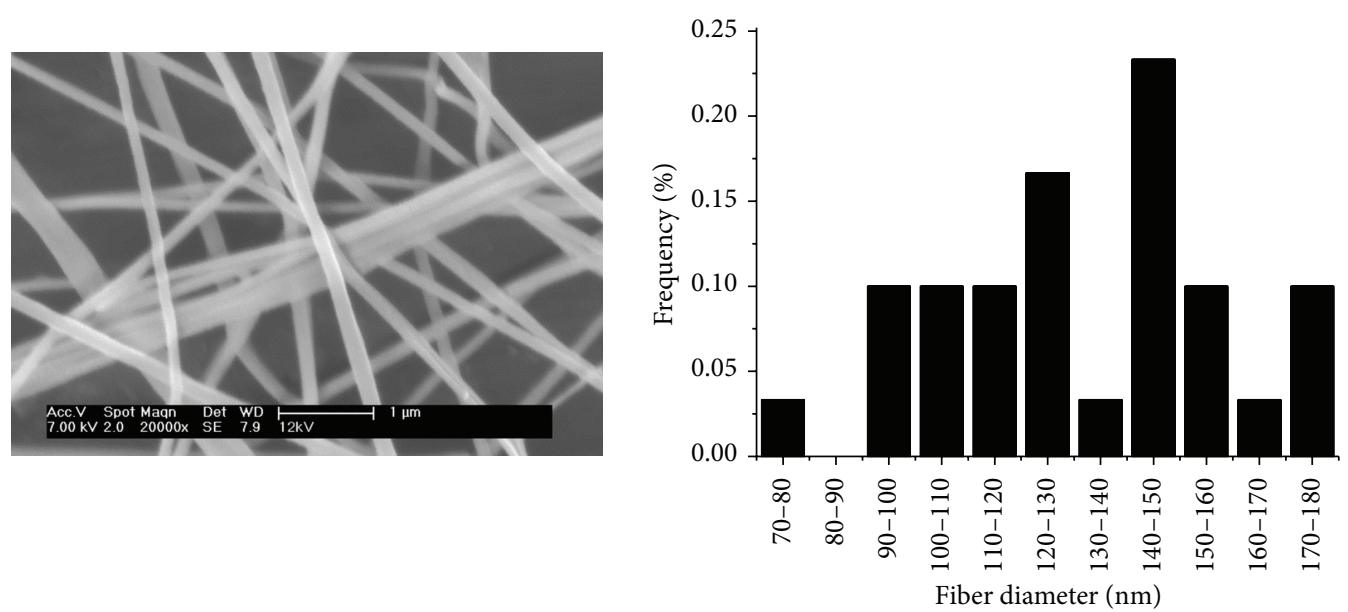

(a)
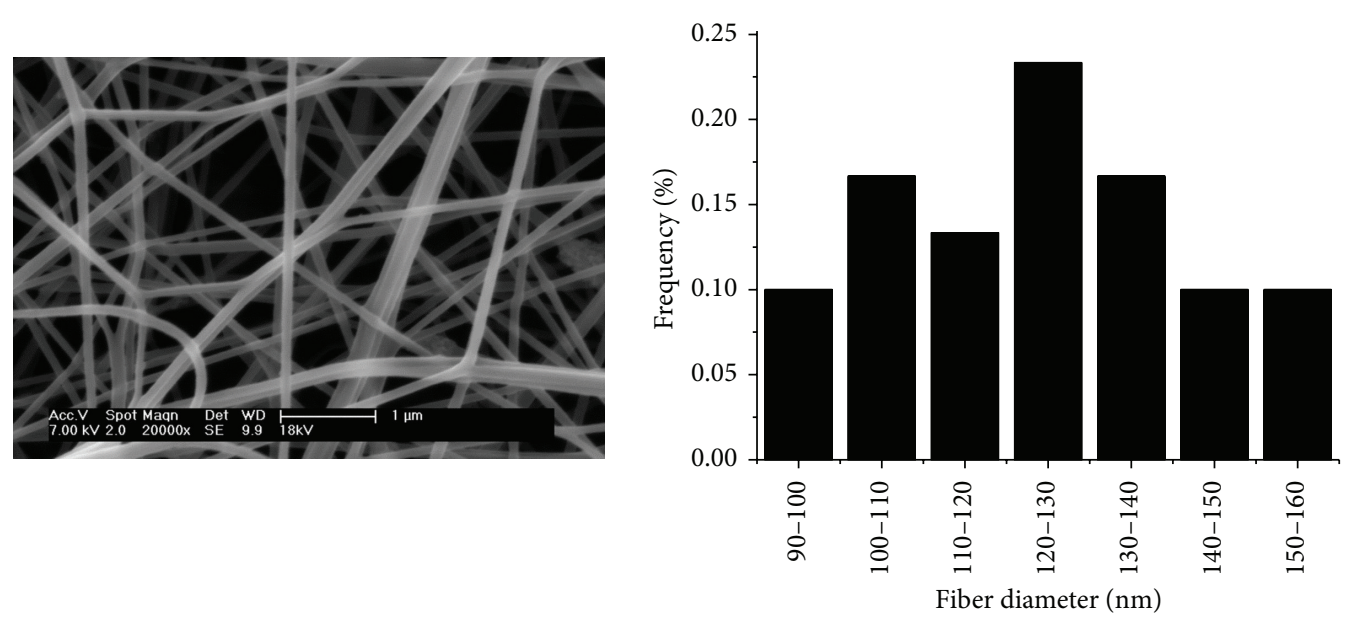

(b)
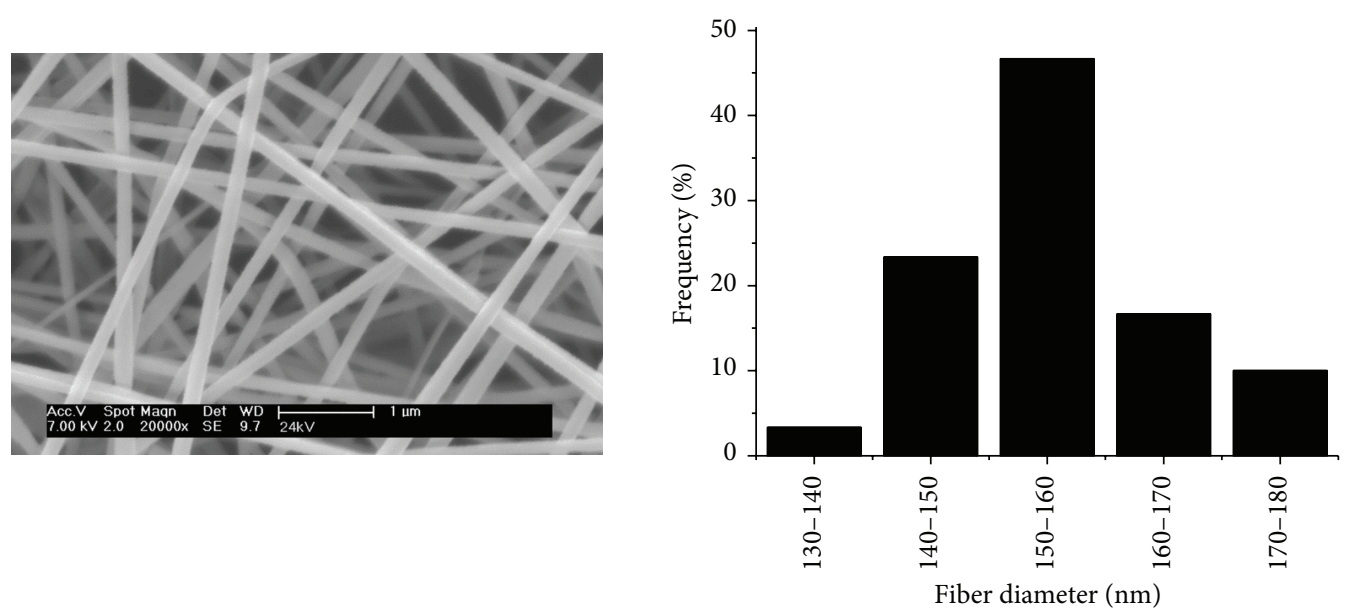

(c)

FIGURE 3: Effect of voltage on fiber morphology and diameter distribution with 1:1 NaAlg/PEO ratio and 5\% solution concentration (magnification $=20,000 \mathrm{x}$ ). Voltage: (a) $12 \mathrm{kV}$; (b) $18 \mathrm{kV}$; (c) $24 \mathrm{kV}$. 
diffraction (PXRD) was performed to analyze the crystalline nature of alginate nanofibers. By using a desktop miniflex $\mathrm{X}$-ray powder diffractometer (Rigaku Inc.) controlled by DIFFRACPLUS software, samples composed of nanofiber mats were scanned at a wavelength of $1.5406 \AA$ from $4^{\circ}$ to $40^{\circ}$ with a step size of $0.03^{\circ}$. The thermal properties and crystallinity of electrospun alginate nanofibers with different $\mathrm{NaAlg} / \mathrm{PEO}$ ratios were determined quantitatively through the analysis of DSC (FP85 TA Cell, Mettler-Toledo Ltd.) instrument coupled with a liquid nitrogen cooling system. All samples were weighed by Mettler MT5 and tested in crimped aluminum pans with a heating rate controlled at $10^{\circ} \mathrm{C} / \mathrm{min}$. The measuring temperature ranges from $30^{\circ} \mathrm{C}$ to $140^{\circ} \mathrm{C}$. The tensile properties of uncoated and nanocoated PLA yarns with different twist levels were measured on an Instron 4412 tester by using a load cell of $100 \mathrm{~N}$ with a constant crosshead speed of $10 \mathrm{~mm} / \mathrm{min}$. Three specimens were measured for each PLA yarn with the same treatment.

\section{Results and Discussions}

3.1. Effect of Solution Concentration on the Morphology and Diameter of Electrospun Nanofibers. In order to improve the spinnability, PEO was added into the alginate solution as a supporting polymer. With the flow rate, applied voltage, and working distance controlled at $0.4 \mathrm{~mL} / \mathrm{h}, 12 \mathrm{kV}$, and $16 \mathrm{~cm}$, respectively, and the sodium $\mathrm{NaAlg} / \mathrm{PEO}$ ratio kept at 1:1, the solution concentration was varied from 1 to $5 \mathrm{wt} \%$ to analyze its influence on the quality of electrospun fibers. As it is shown in Figure 2, beads-on-string structures can be clearly seen in the fibers spun from solution concentrations ranging from 1 to $2 \%$. However, with the increase of concentration within this range, the bead frequency gradually decreases. It can also be observed that the shape of beads shifted from spherical to spindle-like when the solution concentration rises from 2 to $4 \%$. Meanwhile, the fibrous structure improves dramatically in which the number of spindle-like formations is significantly reduced. For the 5\% solution, smooth fibers are formed without any defects.

For the bicomponent solution with total concentration less than $3 \%$, average diameters varying from 32 to $53 \mathrm{~nm}$ can be observed from the resultant electrospun fiber mats. This is smaller than the diameters (97 and $132 \mathrm{~nm}$ ) produced from 4 and $5 \%$ concentrations and is primarily due to the existence of more bead- or spindle-like defects which reduce the mass transfer onto the fiber stem. In addition, two neighboring beads or spindles also play an additional role in further stretching the connecting fiber stem. On the whole, the average diameter and distribution of resultant fibers increase when the solution concentration becomes higher. This is similar to results reported in the literature [15].

3.2. Effect of Electric Voltage on the Morphology and Diameter of Electrospun Nanofibers. At constant flow rate $(0.4 \mathrm{~mL} / \mathrm{h})$, working distance $(16 \mathrm{~cm})$, solution concentration $(5 \%)$, and $\mathrm{NaAlg} / \mathrm{PEO}$ ratio $(1: 1)$, the applied voltage was varied from 0 to $30 \mathrm{kV}$ in order to study the effects of the applied voltage and to obtain the optimum processing voltage.

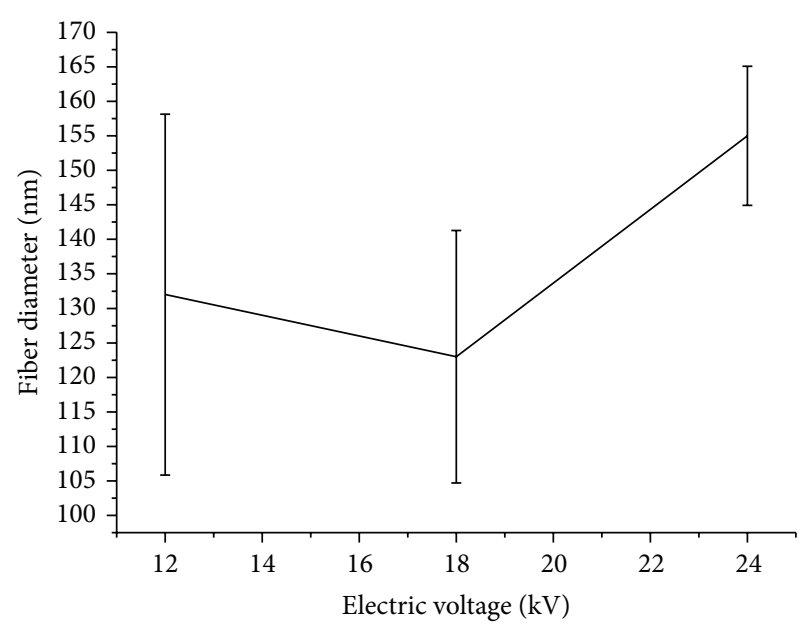

Figure 4: Average diameters of NaAlg/PEO nanofibers at different voltages.

The result indicates that continuous liquid jet is formed when the voltage is between 12 and $24 \mathrm{kV}$. When the voltage is too low or too high, spinning becomes either intermittent or fails completely. Three voltages $(12 \mathrm{kV}, 18 \mathrm{kV}$, and $24 \mathrm{kV})$ were selected to further examine the influence of voltage on fiber morphology and diameter.

Figures 3 and 4 depict the nanofiber morphology and diameter distribution, as well as the relationship between the applied voltage and the fiber average diameter. From Figure 4 it can be seen that the fiber diameter is the smallest at $18 \mathrm{kV}$. As the voltage increases initially, the stronger electrostatic field and repulsive forces facilitate the instability and stretching of the jet, leading to the reduction of resultant fiber diameter $[34,35]$. However, further increasing the voltage can shorten the jet flight time before it is deposited in the collector, which counteracts the stretching and thinning effects. As a result, the electrospun fibers thicken as shown in the second part of Figure 4. Furthermore, the error bars indicate that the diameter distribution of $\mathrm{NaAlg} / \mathrm{PEO}$ nanofibers becomes narrower when the voltage increases. This can also be verified from Figure 3. The likely reason for this is that increased voltage provides greater control of the solution jet and improves the jet stability.

3.3. Effect of Sodium/PEO Ratio on the Morphology and Crystallinity of Electrospun Nanofibers. At 5\% solution concentration, three NaAlg/PEO ratios, $1: 3,1: 1$, and $3: 1$, were used to study the resultant fiber morphology and diameter. As shown in Figure 5, smooth and uniform nanofibers with an average diameter of $123 \mathrm{~nm}$ are obtained at $\mathrm{NaAlg} / \mathrm{PEO}$ ratio of $1: 3$. By increasing the alginate content up to $50 \%$ (1:1 ratio), smooth nanofibers can still be seen with the average diameter decreasing to $105 \mathrm{~nm}$. However, many spindle-like defects appear when the sodium alginate content increases further. The average diameter of alginate-based fibers decreases with alginate content. Since sodium alginate is an anionic polyelectrolyte, it seems that the charge density of the liquid jet increases, which contributes to the forming 

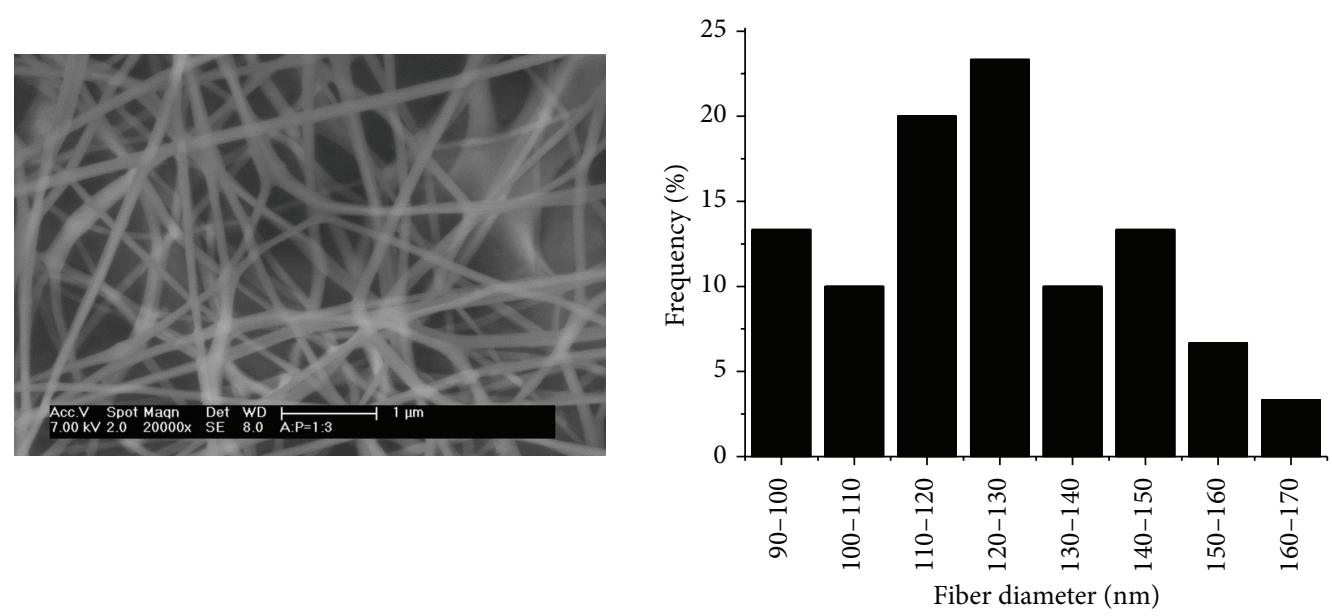

(a)
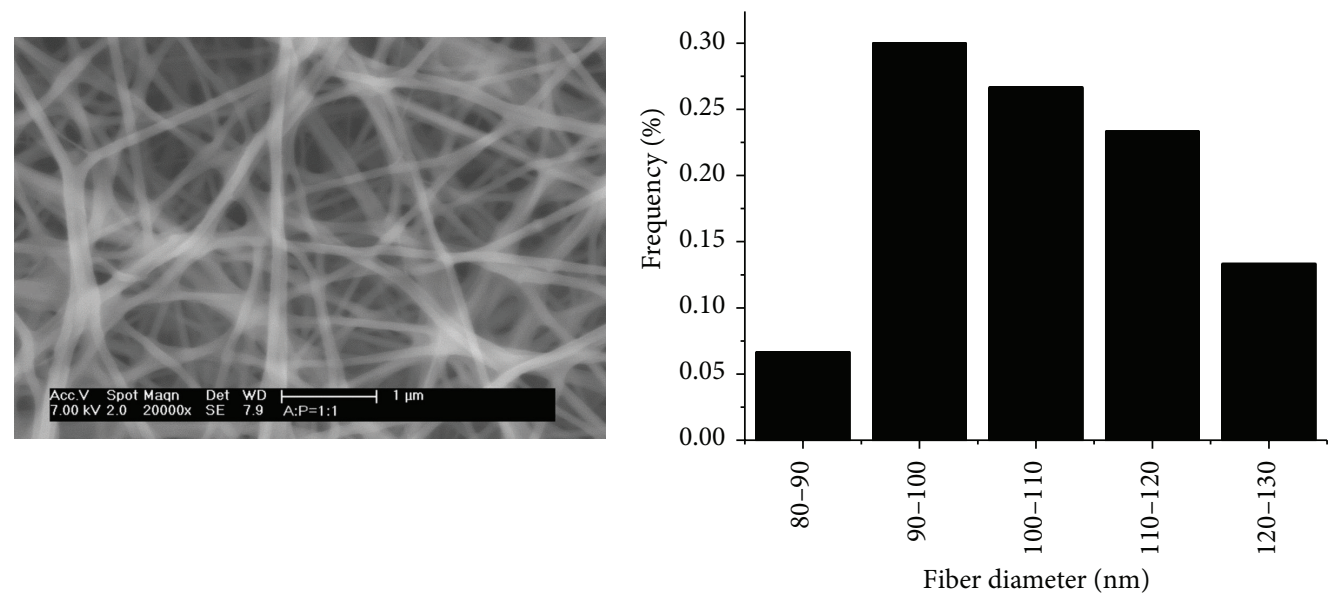

(b)
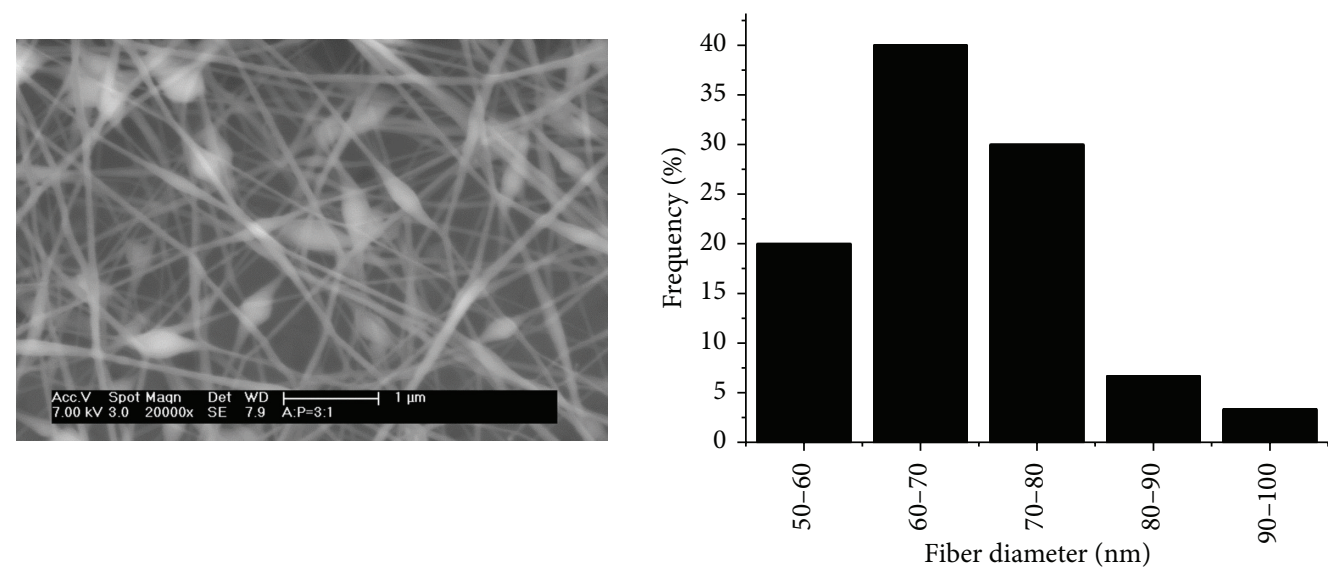

(c)

Figure 5: Effect of the NaAlg/PEO ratio on fiber morphology and diameter distribution with 5\% solution concentration (magnification = 20,000x). NaAlg/PEO ratio: (a) $1: 3$; (b) $1: 1$; (c) $3: 1$.

of finer fibers when the ratio of alginate to PEO rises in the mixed solution.

FTIR spectroscopy of electrospun fibers from solutions with varying sodium $\mathrm{NaAlg} / \mathrm{PEO}$ ratios was conducted to detect any peak shifts that can indicate molecular interactions, such as hydrogen bonding or complexation, between these two mixed polymers $[12,36]$. Figure 6 shows the FTIR spectra of the pure PEO and alginate-based nanofibers in 


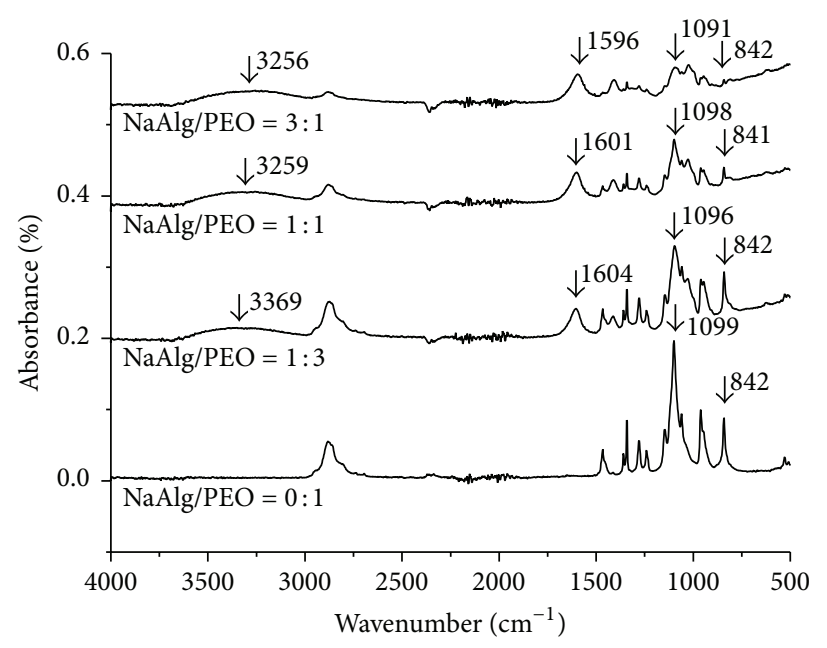

FIgURE 6: The FTIR spectra of alginate-based nanofibers with different NaAlg/PEO ratios.

the wavelength between 600 and $4000 \mathrm{~cm}^{-1}$. The characteristic bands for sodium alginate are in the regions of 3500 and $1600 \mathrm{~cm}^{-1}$, representing the hydroxyl groups and the asymmetric $-\mathrm{COO}^{-}$stretching vibration, respectively. On the other hand, the bands of PEO can be observed at $842 \mathrm{~cm}^{-1}$ and $1099 \mathrm{~cm}^{-1}$ because of the $\mathrm{C}-\mathrm{O}-\mathrm{C}$ bending and asymmetric stretching. Here, typical absorption bands of the pure components are used to characterize the spectrum of $\mathrm{NaAlg} / \mathrm{PEO}$ blend nanofibers with the intensity of each band proportional to the ratios. As to the characteristic bands of $\mathrm{PEO}$, they can be seen in all spectra of blend nanofibers. The region of $\mathrm{C}-\mathrm{O}-\mathrm{C}$ asymmetric stretching vibration at $1099 \mathrm{~cm}^{-1}$ becomes broader compared to pure PEO. This change reveals that hydrogen bonding is the underpinning mechanism in the interaction between sodium alginate and PEO. Besides, the absorption maxima of stretching vibration also shifts towards lower wavenumbers from 3369 to $3256 \mathrm{~cm}^{-1}$ as sodium alginate component increases. It is also notable that bands relating to the hydroxyl stretching vibration become much wider with the increase of alginate content. This strongly demonstrates the mutual interaction of sodium alginate and PEO via the formation of hydrogen bonds between the hydroxyl groups of sodium alginate and etheric oxygen of PEO.

Figure 7 illustrates the PXRD patterns of the as-spun $\mathrm{NaAlg} / \mathrm{PEO}$ nanofibers with mass ratios of $1: 1,1: 3,3: 1$, and $0: 1$. As shown in Figure 7, no distinct peak appears in the curve of alginate powder, implying that its chemical structure is totally amorphous [37]. The pure PEO nanofiber PXRD pattern shows two large peaks at $19.2^{\circ}$ and $23.2^{\circ}$, corresponding to the (120) and (112) crystallographic planes from the PEO $[38,39]$. It demonstrates that the electrospun PEO fibers possess a certain degree of crystallinity. However, as the sodium alginate was mixed with PEO, the intensity of diffraction peaks at the same angles become smaller and lower, indicating the decrease of crystallinity of the resultant nanofiber from the NaAlg/PEO solution. Moreover, this decrease is proportional to the increase of sodium alginate content. The reduction of the crystallinity of the electrospun $\mathrm{NaAlg} / \mathrm{PEO}$ blend fibers is probably a result of the hydrogen bond interaction from these two macromolecules.

In order to further study the variation of crystallinity, the DSC method was utilized to obtain the relevant thermal energy as a function of temperature. In a typical experiment, the latent heat with respect to the thermodynamic transition can produce an endothermic peak in the DSC pattern as the temperature reaches the crystalline melting temperature $\left(T_{m}\right)$. Based on the location of the peak, the crystallite chemistry of the nanofiber sample can be analyzed on a quantitative basis. Figure 8 shows the DSC curves of electrospun nanofibers. It is noticeable that a relatively large and sharp endothermic peak emerged at $76.14^{\circ} \mathrm{C}$ for the pure PEO nanofiber. By adding the sodium alginate component of $25 \%$, $50 \%$, and $75 \%$, the peak of $\mathrm{NaAlg} / \mathrm{PEO}$ blend fiber is shifted to $68.10^{\circ} \mathrm{C}, 64.68^{\circ} \mathrm{C}$, and $61.27^{\circ} \mathrm{C}$, respectively. It indicates that with the increase of alginate content, the crystallinity of the resultant fibers decreases, since the melting temperature decreases. This finding corresponds to the findings in the PXRD experiment.

From the above DSC patterns, crystallinity $\left(X_{c}\right)$ of PEO in blended nanofiber samples can be calculated via the following equation [36]:

$$
X_{c}=\frac{\Delta H}{f_{w} \Delta H_{0}},
$$

where $\Delta H$ is the heat of fusion for the nanofiber sample, $\Delta H_{0}=188.10 \mathrm{~J} / \mathrm{g}$ is the heat of fusion for $100 \%$ crystalline $\mathrm{PEO}$, and $f_{w}$ is the mass fraction of PEO component in the blend nanofibers. Figure 9 shows the trends of melting point $\left(T_{m}\right)$ and crystallinity $\left(X_{c}\right)$ with the ratio of sodium alginate to PEO. It can be observed that both $T_{m}$ and $X_{c}$ decrease with the increase of sodium alginate content. This finding was also reported by Moon and his coworkers [40]. The reason for the above may be the internal stiff structure in the sodium alginate molecular chains which plays an essential role in the overall chain mobility of the blend system and acts as 


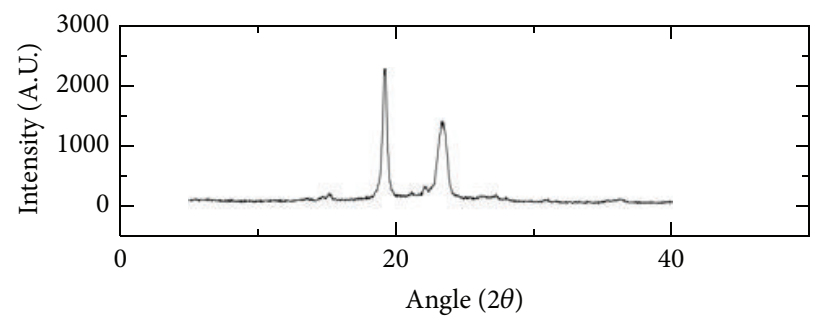

- Alginate $/ \mathrm{PEO}=0: 1$

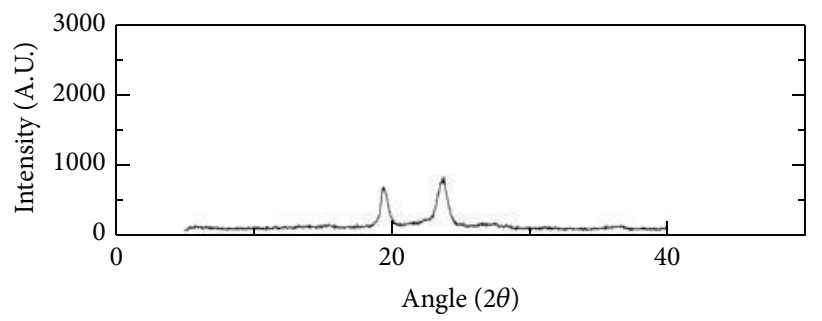

- Alginate/PEO $=1: 3$

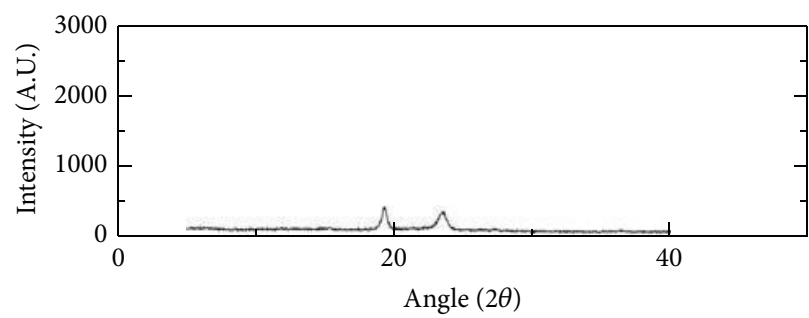

- Alginate $/ \mathrm{PEO}=1: 1$

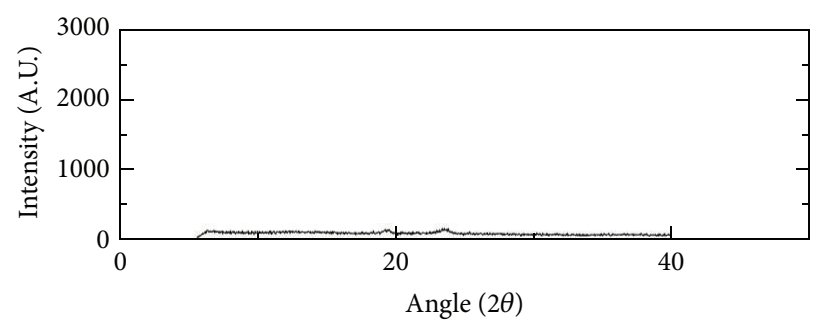

— Alginate $/ \mathrm{PEO}=3: 1$

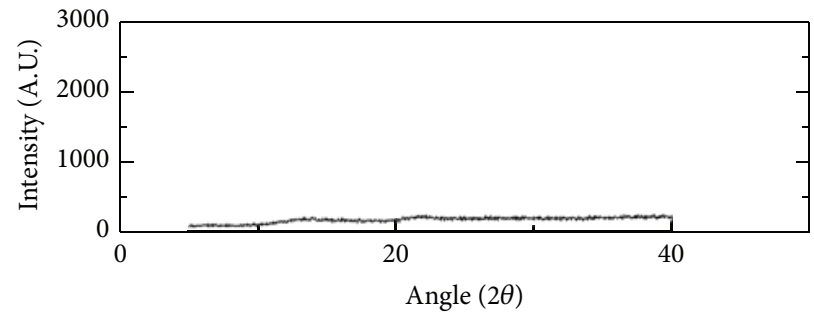

- Alginate/PEO $=1: 0$

FIGURE 7: PXRD patterns of electrospun nanofibers from $5 \%$ solution concentration with different NaAlg/PEO ratios. 


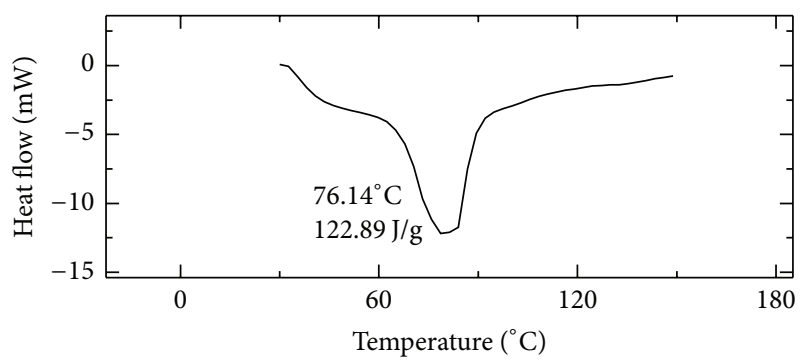

_ Alginate $/ \mathrm{PEO}=0: 1$

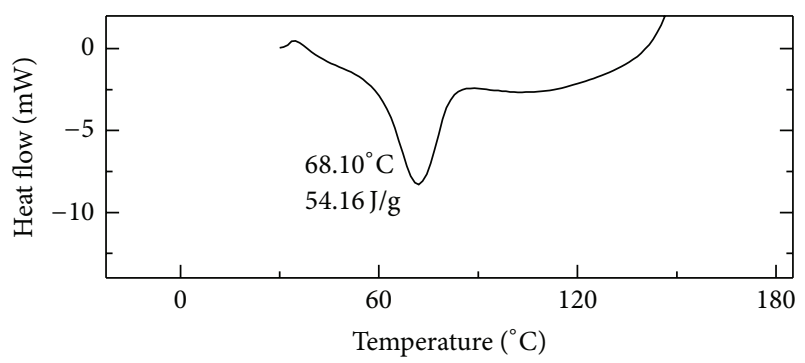

- Alginate $/ \mathrm{PEO}=1: 3$

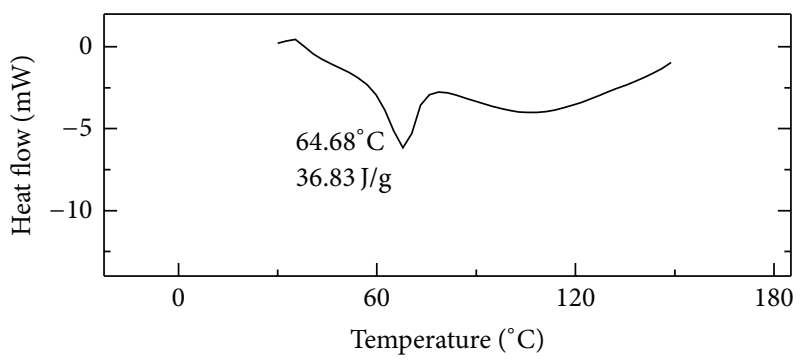

- Alginate $/ \mathrm{PEO}=1: 1$

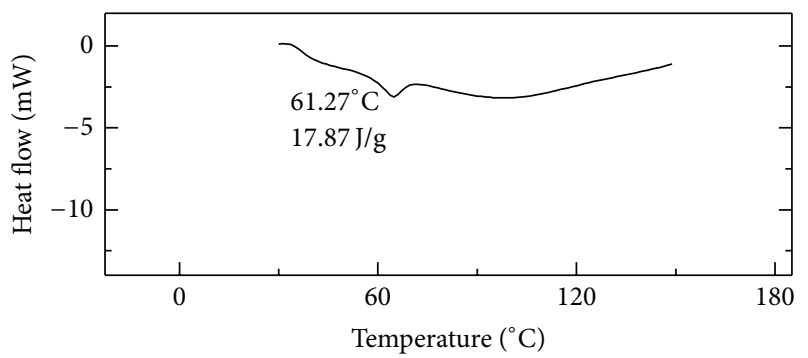

- Alginate $/ \mathrm{PEO}=3: 1$

FIGURE 8: DSC patterns of electrospun nanofibers from $5 \%$ solution concentration with different $\mathrm{NaAlg} / \mathrm{PEO}$ ratios.

a retardant for the crystal growth in the nanofiber forming process [36].

3.4. Tensile Strength of Uncoated and Nanocoated PLA Yarn with Different Twist Levels. The tensile properties of PLA yarns depend on the internal unidirectional filaments. Figure 10 shows the influence of twist on the tensile strength of nanocoated hybrid yarns and uncoated PLA yarns. It can be seen that, with the increase of twist, the tensile strength of hybrid yarns and the tensile strength of uncoated yarns

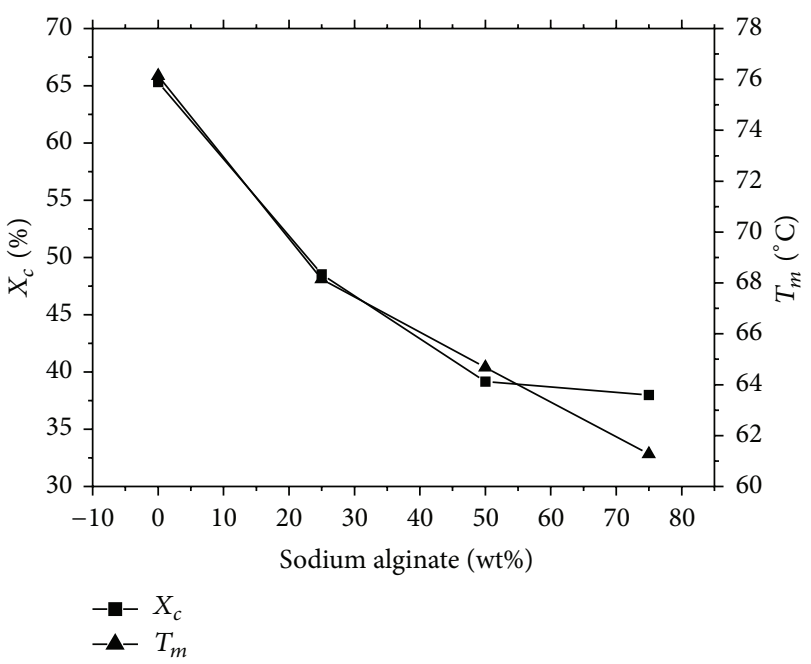

FIGURE 9: Crystallinity and melting point of electrospun $\mathrm{NaAlg} / \mathrm{PEO}$ nanofibers with different alginate contents.

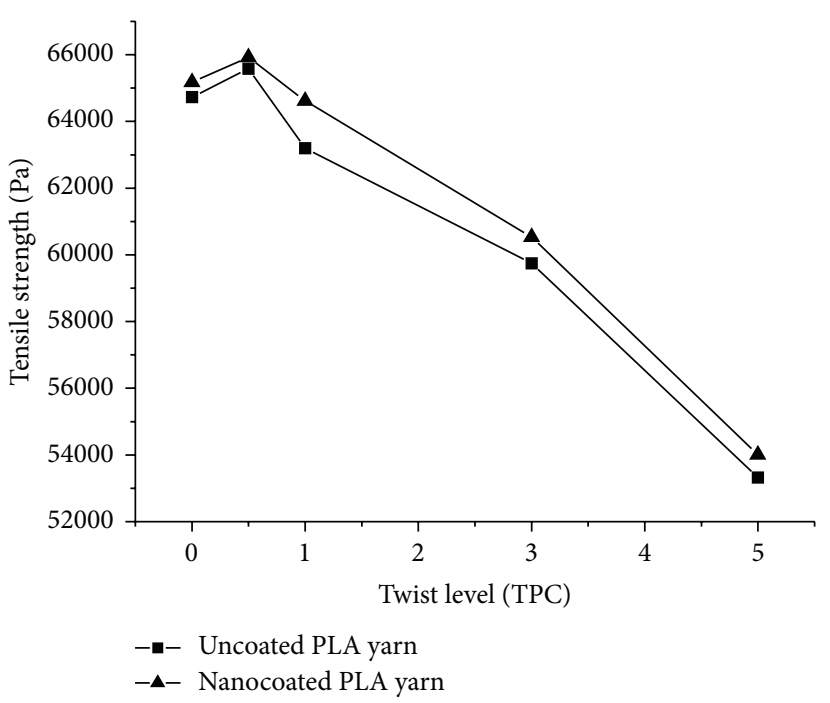

FIgURE 10: Tensile strength of uncoated and nanocoated PLA yarns at different twist levels.

both increase initially (up to 0.5 TPC) and then decrease with further increase of TPC. With a small amount of twist, the binding force holds the filaments together and enhanced their cohesion, which reduces the effect of any weak points in the yarn. However, as the yarn is twisted more, the filaments become less and less aligned in the yarn length direction and this leads to further reduction of yarn strength. It can also be seen that the tensile strength of NaAlg/PEO nanofibercoated hybrid yarns is higher than that of uncoated PLA yarns. Coating of electrospun fibers contributes to the mutual entanglement of nanofibers and filaments inside the yarn body [32], which increases the filament cohesion in the yarn and improves the yarn strength. 


\section{Conclusions}

Sodium alginate, a biocompatible and biodegradable polymer, was successfully electrospun into nanofibers after blending with PEO. The spinnability of the biconstituent solution can be controlled with the variation of solution concentration, applied voltage, and NaAlg/PEO ratio. The results show that the electrospinning of alginate-based fibers has a relatively wide applied voltage window from 12 to $24 \mathrm{kV}$. Smooth and homogeneous fibers with a narrow diameter distribution were obtained at $5 \%$ concentration with the $\mathrm{NaAlg} / \mathrm{PEO}$ ratio of $1: 1$. Furthermore, the resultant nanofiber from electrospinning was also directly coated on PLA yarn to make a hybrid yarn. In general, the nanocoated yarn possesses better tensile properties than the uncoated yarns. A small amount of twist can further improve the hybrid yarn strength. The production of NaAlg/PEO nanofiber-coated yarns makes it possible to fabricate more sophisticated structures for biological and medical applications using techniques such as weaving or knitting.

\section{Conflict of Interests}

The authors declare that there is no conflict of interests regarding the publication of this paper.

\section{References}

[1] A. I. Usov, "Alginic acids and alginates: analytical methods used for their estimation and characterisation of composition and primary structure," Russian Chemical Reviews, vol. 68, no. 11, pp. 957-966, 1999.

[2] H. Chèze-Lange, D. Beunard, P. Dhulster et al., "Production of microbial alginate in a membrane bioreactor," Enzyme and Microbial Technology, vol. 30, no. 5, pp. 656-661, 2002.

[3] I. Donati and S. Paoletti, "Material properties of alginates," in Alginates: Biology and Applications, H. A. B. Rehm, Ed., vol. 13 of Microbiology Monographs, chapter 1, pp. 1-53, Springer, Dordrecht, The Netherlands, 2009.

[4] A. Martinsen, G. Skjak-Braek, and O. Smidsrod, "Alginate as immobilization material: I. Correlation between chemical and physical properties of alginate gel beads," Biotechnology and Bioengineering, vol. 33, no. 1, pp. 79-89, 1989.

[5] M. Avella, E. D. Pace, B. Immirzi, G. Impallomeni, M. Malinconico, and G. Santagata, "Addition of glycerol plasticizer to seaweeds derived alginates: influence of microstructure on chemical-physical properties," Carbohydrate Polymers, vol. 69, no. 3, pp. 503-511, 2007.

[6] J.-S. Yang, Y.-J. Xie, and W. He, "Research progress on chemical modification of alginate: a review," Carbohydrate Polymers, vol. 84, no. 1, pp. 33-39, 2011.

[7] H. T. Bu, A. L. Kjoniksen, K. D. Knudsen, and B. Nystrom, "Rheological and structural properties of aqueous alginate during gelation via the ugi multicomponent condensation reaction," Biomacromolecules, vol. 5, pp. 1470-1479, 2004.

[8] Y. S. Choi, S. R. Hong, Y. M. Lee, K. W. Song, M. H. Park, and Y. S. Nam, "Study on gelatin-containing artificial skin: I. Preparation and characteristics of novel gelatin-alginate sponge," Biomaterials, vol. 20, no. 5, pp. 409-417, 1999.

[9] B. Balakrishnan, M. Mohanty, P. R. Umashankar, and A. Jayakrishnan, "Evaluation of an in situ forming hydrogel wound dressing based on oxidized alginate and gelatin," Biomaterials, vol. 26, no. 32, pp. 6335-6342, 2005.

[10] C. A. Bonino, K. Efimenko, S. I. Jeong, M. D. Krebs, E. Alsberg, and S. A. Khan, "Three-dimensional electrospun alginate nanofiber mats via tailored charge repulsions," Small, vol. 8, no. 12, pp. 1928-1936, 2012.

[11] C. Kriegel, A. Arrechi, K. Kit, D. J. McClements, and J. Weiss, "Fabrication, functionalization, and application of electrospun biopolymer nanofibers," Critical Reviews in Food Science and Nutrition, vol. 48, no. 8, pp. 775-797, 2008.

[12] S. Safi, M. Morshed, S. A. Hosseini Ravandi, and M. Ghiaci, "Study of electrospinning of sodium alginate, blended solutions of sodium alginate/poly(vinyl alcohol) and sodium alginate/poly(ethylene oxide)," Journal of Applied Polymer Science, vol. 104, no. 5, pp. 3245-3255, 2007.

[13] H. Nie, A. He, W. Wu et al., "Effect of poly(ethylene oxide) with different molecular weights on the electrospinnability of sodium alginate," Polymer, vol. 50, no. 20, pp. 4926-4934, 2009.

[14] W. C. Li, Y. H. Guan, H. Z. Li, P. C. Yu, H. M. Luo, and C. L. Lu, "Preparation of drug-loaded polyvinyl alcohol-sodium alginate nanofiber by electrospinning," Chinese Pharmaceutical Journal, vol. 48, pp. 980-985, 2013.

[15] J.-W. Lu, Y.-L. Zhu, Z.-X. Guo, P. Hu, and J. Yu, "Electrospinning of sodium alginate with poly(ethylene oxide)," Polymer, vol. 47, no. 23, pp. 8026-8031, 2006.

[16] N. Bhattarai and M. Zhang, "Controlled synthesis and structural stability of alginate-based nanofibers," Nanotechnology, vol. 18, pp. 5601-5610, 2007.

[17] C. A. Bonino, M. D. Krebs, C. D. Saquing et al., "Electrospinning alginate-based nanofibers: from blends to crosslinked low molecular weight alginate-only systems," Carbohydrate Polymers, vol. 85, no. 1, pp. 111-119, 2011.

[18] S. A. Park, K. E. Park, and W. D. Kim, "Preparation of sodium alginate/poly(ethylene oxide) blend nanofibers with lecithin," Macromolecular Research, vol. 18, no. 9, pp. 891-896, 2010.

[19] V. Leung, R. Hartwell, S. S. Elizei, H. Yang, A. Ghahary, and F. Ko, "Postelectrospinning modifications for alginate nanofiber-based wound dressings," Journal of Biomedical Materials Research Part B, vol. 102, pp. 508-515, 2013.

[20] D. Fang, Y. Liu, S. Jiang, J. Nie, and G. Ma, "Effect of intermolecular interaction on electrospinning of sodium alginate," Carbohydrate Polymers, vol. 85, no. 1, pp. 276-279, 2011.

[21] A. Glawe and A. Giessmann, "Fiber production-coating technologies for functional finishing of yarns and filaments," Chemical Fibers International, vol. 57, no. 3, pp. 131-132, 2007.

[22] B. S. Shim, W. Chen, C. Doty, C. Xu, and N. A. Kotov, "Smart electronic yarns and wearable fabrics for human biomonitoring made by carbon nanotube coating with polyelectrolytes," Nano Letters, vol. 8, no. 12, pp. 4151-4157, 2008.

[23] F.-L. Zhou, R.-H. Gong, and I. Porat, "Nanocoating on filaments by electrospinning," Surface and Coatings Technology, vol. 204, no. 5, pp. 621-628, 2009.

[24] K. Kuraishi, H. Iwata, S. Nakano et al., "Development of nanofiber-covered stents using electrospinning: in vitro and acute phase in vivo experiments," Journal of Biomedical Materials Research Part B: Applied Biomaterials, vol. 88, no. 1, pp. 230239, 2009.

[25] P. Heikkla, A. Sipila, M. Peltola, A. Harlin, and A. Taipale, "Electrospun PA-66 coating on textile surfaces," Textile Research Journal, vol. 77, pp. 864-870, 2007. 
[26] S. Lee and S. K. Obendorf, "Developing protective textile materials as barriers to liquid penetration using meltelectrospinning," Journal of Applied Polymer Science, vol. 102, no. 4, pp. 3430-3437, 2006.

[27] H. Lee, M. Alcoutlabi, J. V. Watson, and X. Zhang, "Electrospun nanofiber-coated separator membranes for lithium-ion rechargeable batteries," Journal of Applied Polymer Science, vol. 129, no. 4, pp. 1939-1951, 2013.

[28] R. Srikar, T. Gambaryan-Roisman, C. Steffes, P. Stephan, C. Tropea, and A. L. Yarin, "Nanofiber coating of surfaces for intensification of drop or spray impact cooling," International Journal of Heat and Mass Transfer, vol. 52, no. 25-26, pp. 58145826, 2009.

[29] E. Gallo, Z. Fan, B. Schartel, and A. Greiner, "Electrospun nanofiber mats coating-new route to flame retardancy," Polymers for Advanced Technologies, vol. 22, no. 7, pp. 1205-1210, 2011.

[30] M. Es-Saheb, A. A. Elzatahry, E. M. Sherif, A. S. Alkaraki, and E. R. Kenawy, "A novel electrospinning application for polyvinyl chloride nanofiber coating deposition as a corrosion inhibitor for aluminum, steel, and brass in chloride solutions," International Journal of Electrochemical Science, vol. 7, no. 7, pp. 5962-5976, 2012.

[31] A. Thorvaldsson, H. Stenhamre, P. Gatenholm, and P. Walkenström, "Electrospinning of highly porous scaffolds for cartilage regeneration," Biomacromolecules, vol. 9, no. 3, pp. 1044-1049, 2008.

[32] F.-L. Zhou, R.-H. Gong, and I. Porat, "Nano-coated hybrid yarns using electrospinning," Surface and Coatings Technology, vol. 204, no. 21-22, pp. 3459-3463, 2010.

[33] F. Rombaldoni, K. Mahmood, A. Varesano et al., "Adhesion enhancement of electrospun nanofiber mats to polypropylene nonwoven fabric by low-temperature oxygen plasma treatment," Surface and Coatings Technology, vol. 216, pp. 178-184, 2013.

[34] Y. M. Shin, M. M. Hohman, M. P. Brenner, and G. C. Rutledge, "Experimental characterization of electrospinning: the electrically forced jet and instabilities," Polymer, vol. 42, no. 25, pp. 9955-9967, 2001.

[35] Y. M. Shin, M. M. Hohman, M. P. Brenner, and G. C. Rutledge, "Electrospinning: a whipping fluid jet generates submicron polymer fibers," Applied Physics Letters, vol. 78, no. 8, pp. 11491151, 2001.

[36] T. Çaykara, S. Demirci, M. S. Eroğlu, and O. Güven, "Poly(ethylene oxide) and its blends with sodium alginate," Polymer, vol. 46, no. 24, pp. 10750-10757, 2005.

[37] T. Tripathy, S. R. Pandey, N. C. Karmakar, R. P. Bhagat, and R. P. Singh, "Novel flocculating agent based on sodium alginate and acrylamide," European Polymer Journal, vol. 35, no. 11, pp. 20572072, 1999.

[38] N. Bhattarai, Z. Li, D. Edmondson, and M. Zhang, "Alginatebased nanofibrous scaffolds: structural, mechanical, and biological properties," Advanced Materials, vol. 18, no. 11, pp. 14631467, 2006.

[39] J. M. Deitzel, J. D. Kleinmeyer, J. K. Hirvonen, and N. C. Tan, "Controlled deposition of electrospun poly(ethylene oxide) fibers," Polymer, vol. 42, no. 19, pp. 8163-8170, 2001.

[40] S. Moon, B.-Y. Ryu, J. Choi, B. Jo, and R. J. Farris, "The morphology and mechanical properties of sodium alginate based electrospun poly(ethylene oxide) nanofibers," Polymer Engineering and Science, vol. 49, no. 1, pp. 52-59, 2009. 

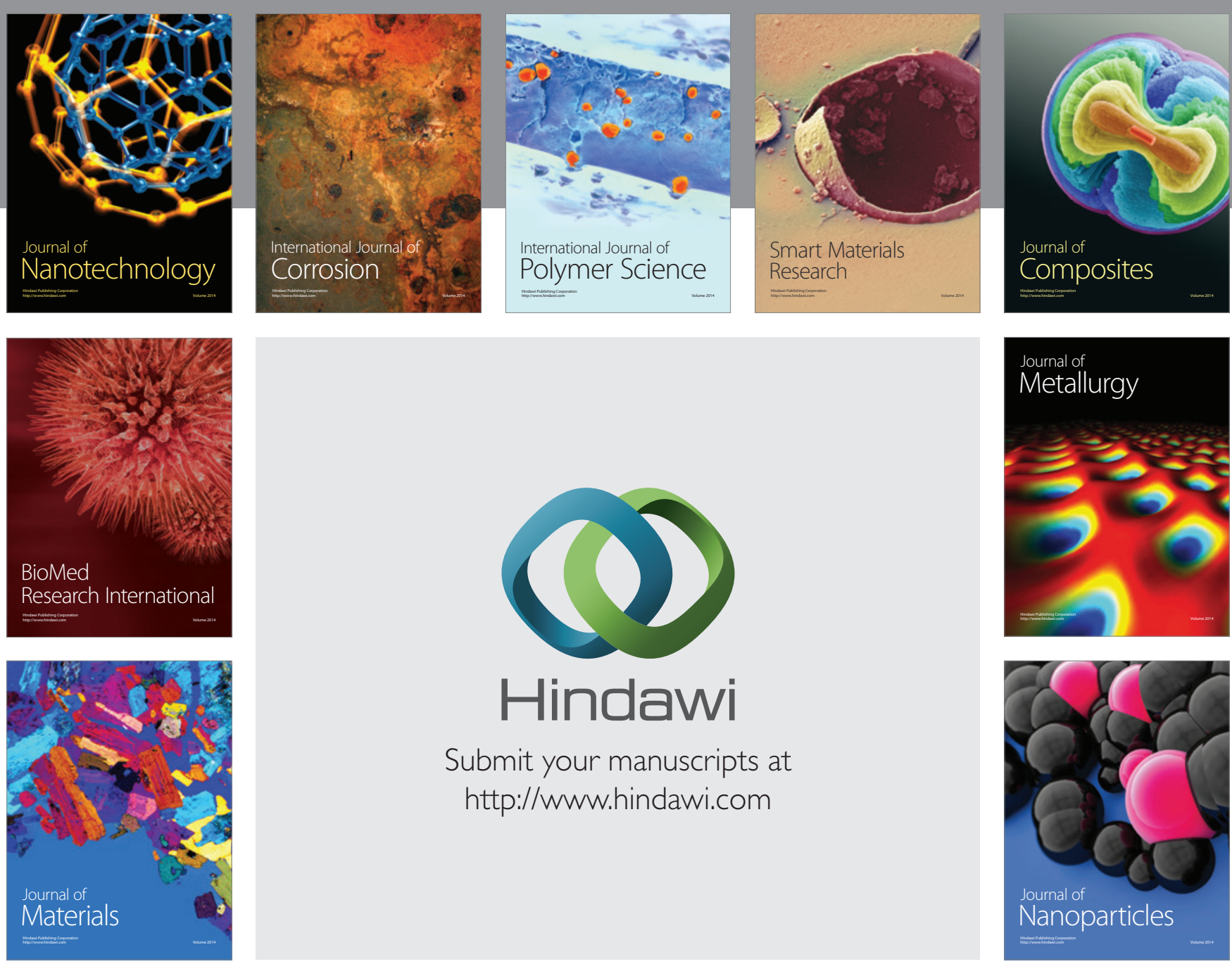

Submit your manuscripts at http://www.hindawi.com
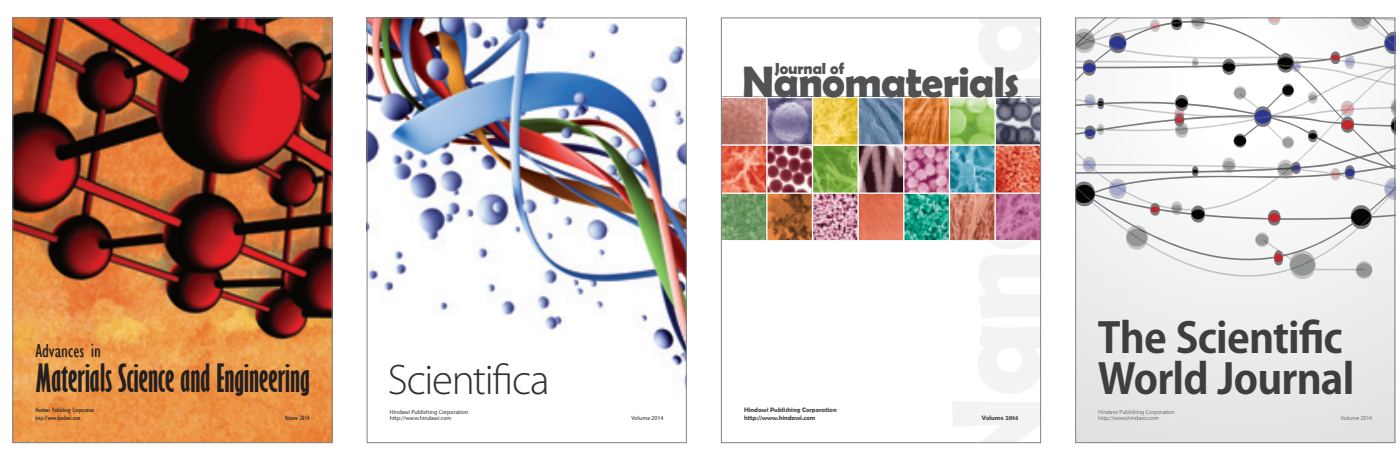

\section{The Scientific World Journal}
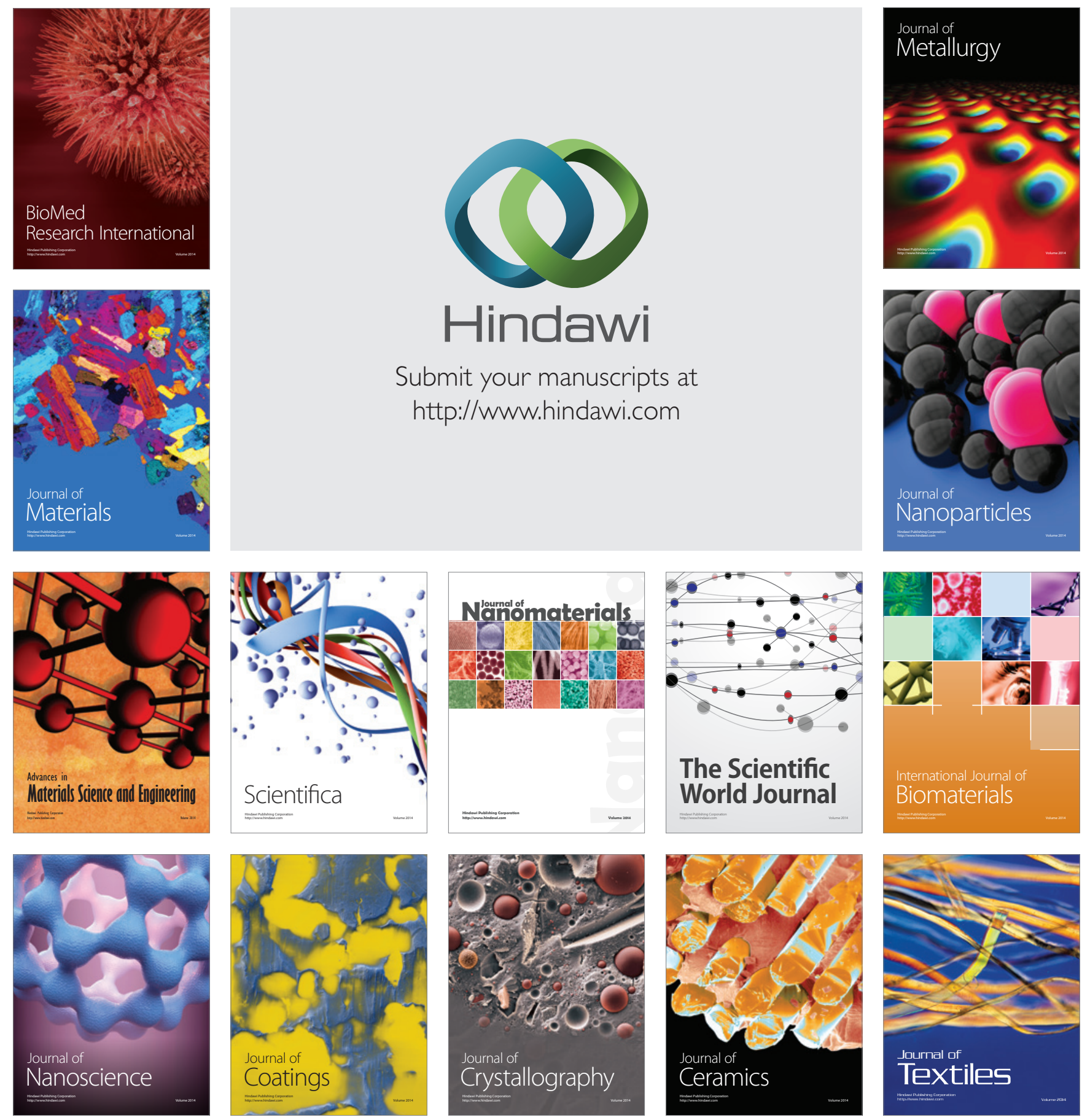